\title{
Preoperative computer tomography-guided indocyanine green injection is associated with successful localization of small pulmonary nodules
}

\author{
Xukai Li ${ }^{1,2 \#}$, Ke Xu${ }^{1 \#}$, Renli Cen ${ }^{3 \#}$, Jinghui Deng ${ }^{4}$, Zhexue Hao ${ }^{1}$, Jun Liu ${ }^{1}$, Hiromitsu Takizawa ${ }^{5}$, \\ Calvin S. H. Ng ${ }^{6}$, Giuseppe Marulli ${ }^{7}$, Min P. Kim ${ }^{8}$, Fei Cui ${ }^{1}$, Jianxing $\mathrm{He}^{1}$
}

${ }^{1}$ Department of Thoracic Surgery and Oncology, the First Affiliated Hospital of Guangzhou Medical University, State Key Laboratory of Respiratory Disease, National Clinical Research Center for Respiratory Disease, Guangzhou Institute of Respiratory Health, Guangzhou, China; ${ }^{2}$ Department of Cardiothoracic Surgery, Guangdong Second Provincial General Hospital, Guangzhou, China; ${ }^{3}$ Department of Radiology, The First Affiliated Hospital of Guangzhou Medical University, Guangzhou, China; ${ }^{4}$ Department of Clinical Medicine, the Third Clinical School of Guangzhou Medical University, Guangzhou, China; ${ }^{5}$ Department of Thoracic and Endocrine Surgery and Oncology, Institute of Biomedical Sciences, Tokushima University Graduate School, Tokushima, Japan; ${ }^{6}$ Division of Cardiothoracic Surgery, Department of Surgery, Prince of Wales Hospital, the Chinese University of Hong Kong, Hong Kong, China; ${ }^{7}$ Thoracic Surgery Unit, Department of Emergency and Organ Transplantation (DETO), University Hospital of Bari, Bari, Italy; ${ }^{8}$ Division of Thoracic Surgery, Department of Surgery, Houston Methodist Hospital, Houston, TX, USA

Contributions: (I) Conception and design: All authors; (II) Administrative support: J Liu, J He; (III) Provision of study materials or patients: R Cen, K Xu, J He; (IV) Collection and assembly of data: X Li, J Deng, Z Hao; (V) Data analysis and interpretation: X Li, F Cui; (VI) Manuscript writing: All authors; (VII) Final approval of manuscript: All authors.

\#These authors contributed equally to this work.

Correspondence to: Fei Cui, MD; Jianxing He, MD. Department of Thoracic Surgery, The First Affiliated Hospital of Guangzhou Medical University, 151 Yanjiang Road, Guangzhou 510120, China. Email: cuidavil@hotmail.com; drjianxing.he@gmail.com.

Background: Localization of small pulmonary nodules (SPNs) is challenging in minimally invasive pulmonary resection, and it is unknown whether computer tomography (CT) guided by indocyanine green (ICG) can provide accurate localization with minimal complications.

Methods: We performed a retrospective study of patients who underwent thoracoscopic resection of pulmonary nodules after CT-guided preoperative localization with ICG from May 2019 to May 2020. Demographics, procedural data, postoperative complications, and pathologic information, were collected, and an analysis of the accuracy and complications after surgery was conducted.

Results: In 471 patients, there was a total of 512 peripheral pulmonary nodules that were $\leq 2 \mathrm{~cm}$ in size. The average time for CT-guided percutaneous ICG injection for localization was 18 minutes, and $98.4 \%$ (504/512) of the nodules were successfully localized. The average size of the nodules was $9.1 \mathrm{~mm}$, and the average depth from the pleural surface was $8.9 \mathrm{~mm}$. Overall, $5.9 \%(28 / 471)$ of the patients had asymptomatic pneumothorax after localization, but none needed a tube thoracostomy. All the nodules were resected using video-assisted thoracoscopy technique.

Conclusions: Preoperative CT-guided transthoracic ICG injection is safe and feasible for localization of small lung nodules for minimally invasive pulmonary resection. This technique should be considered for preoperative CT-guided localization of small lung nodules.

Keywords: Computed tomography (CT); indocyanine green (ICG); pulmonary nodules; video-assisted thoracoscopic surgery (VATS)

Submitted Apr 09, 2021. Accepted for publication May 26, 2021.

doi: $10.21037 /$ tlcr-21-425

View this article at: http://dx.doi.org/10.21037/tlcr-21-425 


\section{Introduction}

Low-dose spiral computed tomography (CT) is an early lung cancer screening tool, which can reduce lung cancer mortality (1,2). The prevalence of lung cancer screening has led to an increase in the detection rate of small pulmonary nodules (SPNs); however, the characteristics of most of the detected pulmonary nodules cannot usually be determined. These nodules may appear as pure ground-glass nodules, semisolid nodules, or solid nodules under CT $(3,4)$. When these nodules persist, the solid component grows to $\geq 5 \mathrm{~mm}$ and the follow-up nodules show enlargement, and thus obtaining a pathological diagnosis has become increasingly necessary. However, localizing and resecting these pulmonary nodules for pathological evaluation is exceedingly difficult (5). When the nodules are smaller than $20 \mathrm{~mm}$, palpation, particularly of ground-glass types, can be difficult due to their deep location, while conducting CTguided puncture biopsy is also a challenge $(6,7)$.

Preoperative localization of SPNs before video-assisted thoracoscopic surgery (VATS) can improve the accuracy of diagnosis and reduce the incidence rate, operation time, and conversion to thoracotomy (8). Many CT-guided percutaneous puncture and localization techniques, the use different materials, such as hook-wire, micro coil, methylene blue, lipiodol, radionuclide etc., has been widely reported (9-13). Each of these techniques has its advantages and disadvantages. Previously, our center used a fast-acting medical adhesive for localization (14). This adhesive is mainly composed of octyl- $\alpha$-cyanoacrylate and contains polymethacrylate. It is nontoxic and has good biosafety. When the medical adhesive is injected into the lung, the adhesive quickly polymerizes, binds tightly with adjacent tissues, and forms a hard knot, which is convenient for rapid recognition under the thoracoscope. However, if the medical adhesive is fused with the nodule, it can affect pathological evaluation, and there is a risk of embolism if it is inadvertently injected into the blood vessel. Therefore, in May 2019, we began to use indocyanine green (ICG) for CT-guided localization. We performed retrospective analysis of the outcomes of preoperative ICG localization for pulmonary resection. We present the following article in accordance with the STROBE reporting checklist (available at http://dx.doi.org/10.21037/tlcr-21-425).

\section{Methods}

\section{Patient selection}

All the patients enrolled in the study signed the informed consent for CT puncture and localization before operation at the Department of Thoracic Surgery of the First Affiliated Hospital of Guangzhou Medical University. We evaluated the patients who underwent CT-guided percutaneous injection of ICG for preoperative localization and VATS resection of pulmonary nodules. Clinical data were collected from the electronic medical record system, and included patient age, gender, chest CT image, localization time, complications, and postoperative pathology. Selection criteria were as follows: pure ground glass opacities, semisolid, or solid lung nodules with a diameter $>6$ and $<20 \mathrm{~mm}$; and pulmonary nodules located no deeper than $3 \mathrm{~cm}$ from the surface of the visceral pleura.

The ethics committee of the First Affiliated Hospital of Guangzhou Medical University waived institutional review board approval. All procedures performed in this study involving human participants were in accordance with the Declaration of Helsinki (as revised in 2013), and informed consent was provided by all patients.

\section{Statistical analysis of data}

Descriptive statistics are expressed as frequency and percentages of categorical variables (including gender and pathological type), and continuous data are expressed as mean, maximum, and minimum values (including age and nodule size). Data were analyzed with SPSS 25 software (IBM Corp., Armonk, NY, USA).

\section{CT scan}

A 16-slice spiral CT (Aquillion 16, Toshiba, Japan; or Aquillion 64, Siemens, Germany) scan was used for preoperative CT-guided localization. The following scanning criteria were used: $120 \mathrm{kV}, 60 \mathrm{~mA}$, a thickness of $2 \mathrm{~mm}$, a spacing of $2 \mathrm{~mm}$, a pitch of 1.1 seconds, and a rotation time of 0.6 seconds. Patients were told to hold their breath at the end of normal inhalation for scanning.

\section{Localization planning}

For simple, single peripheral nodules, ICG was injected into or around the nodule (Figure 1A). For complex peripheral nodules (for example, after localization of the blind area, or for parafissure, inframammary, and bony structures), ICG was injected into the same horizontal or vertical line of the nodule through axial localization (Figure 1B). For multiple nodules on the same side, 2 puncture needles were used to locate different nodules 

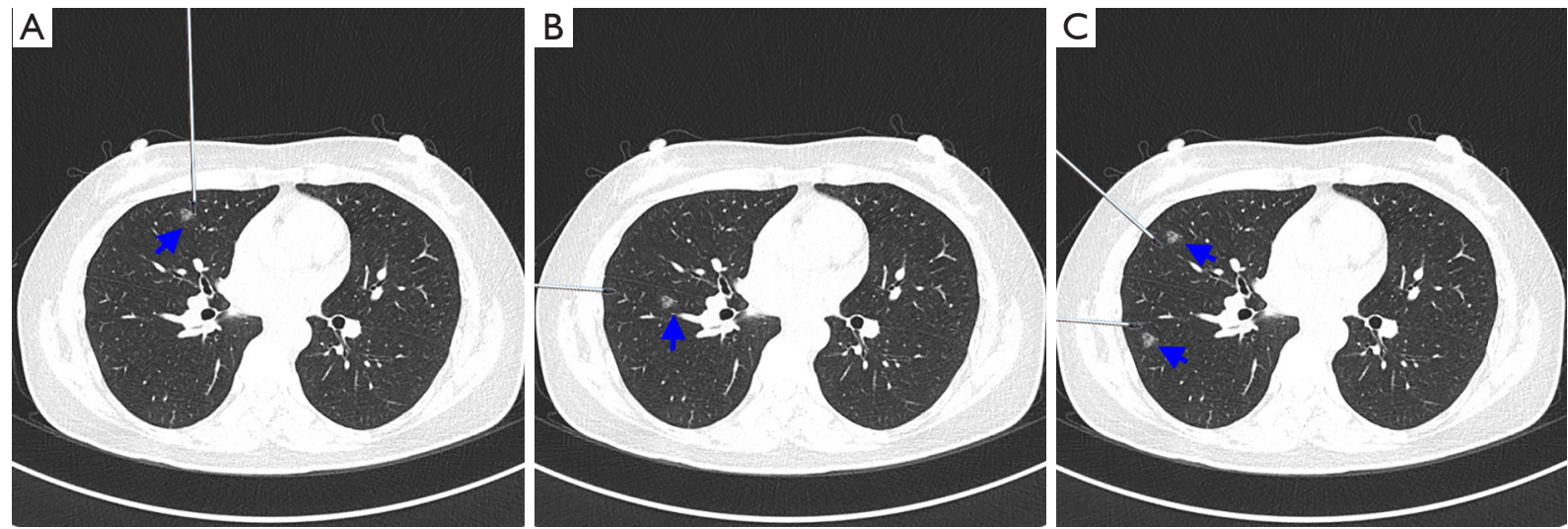

Figure 1 Localization design (blue arrows indicate nodules). (A) The design for single-nodule puncture and localization; (B) the design of the localization of the nodule near the pulmonary fissure; (C) the design for simultaneous localization of the multiple nodules on the same side.

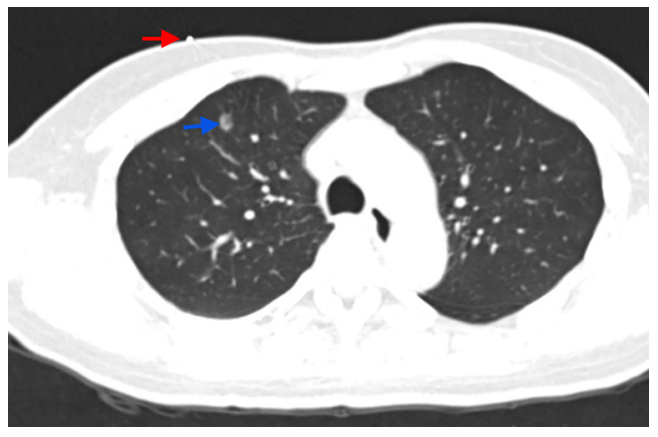

Figure 2 Computed tomography (CT) scan showing an $8-\mathrm{mm}$ ground-glass nodule (GGN; blue arrow) in the right upper lung. The metal marking wire (red arrow) can be observed on the chest wall.

at the same time (requiring simultaneous operation by 2 physicians; Figure 1C).

\section{Localization procedure}

(I) The patient's position (supine position, lateral recumbent position, or prone position) was determined by the radiologist based on the location of the lesion. A metal wire was placed on the chest wall adjacent to the nodule as a marker. The metal mark was fixed on the skin with medical tape (Video 1).

(II) A limited CT scan was performed to identify the lung nodule to reduce the radiation dose received by the patient.

(III) Based on the location of the metal wire and the lesion (Figure 2), the puncture point and angle were determined and marked (with attention being paid to avoid the scapula, ribs, interlobar fissure, and blood vessels). Care was taken to ensure the puncture was perpendicular to the skin surface to shorten the puncture distance, and the distance was measured from the puncture point to the lesion.

(IV) After the area was prepped and draped, $10 \mathrm{~mL}$ of $2 \%$ lidocaine local anesthetic was subcutaneously injected. A 13.8-cm no. 19 biopsy needle (TruGuide, Bard, AZ, USA) was used for transthoracic localization. The tip of the needle reached the lung parenchyma near the pulmonary nodule (Figure 3) and was confirmed with another limited CT scan.

(V) If necessary, the tip of the needle was adjusted according to the second CT image. After the required position of the needle tip was confirmed, the core needle was removed, and the needle sleeve was left at the original position. After confirmation that there was no bleeding after the syringe was withdrawn, a $2-\mathrm{mL}$ syringe was used to immediately to inject $0.4 \mathrm{~mL}$ of ICG $(2.5 \mathrm{mg} / \mathrm{mL}$; Dandong Yichuang Pharmaceutical Co., Ltd., China) with $0.8 \mathrm{~mL}$ of normal saline. The needle sleeve was then removed, and the puncture point was covered by an aseptic application.

(VI) The chest CT (Figure 4) was re-examined to confirm the puncture position and determine whether there were any complications. The patient was then sent to the operating room, and the puncture operation time and complications were recorded. 


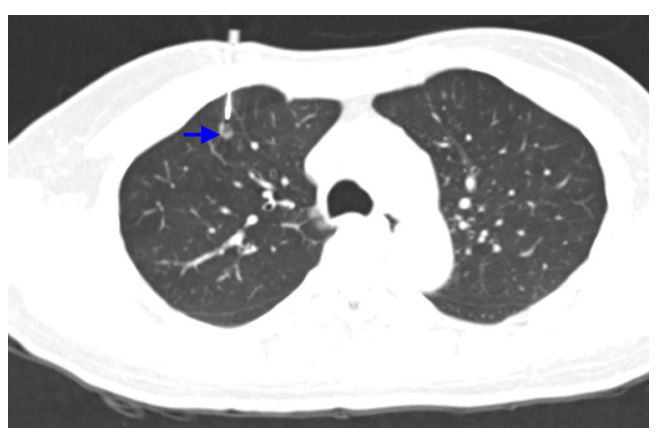

Figure 3 The puncture needle is inserted into the lung parenchyma until it reaches the side of the nodule (blue arrow) $1 \mathrm{~cm}$ below the pleura.

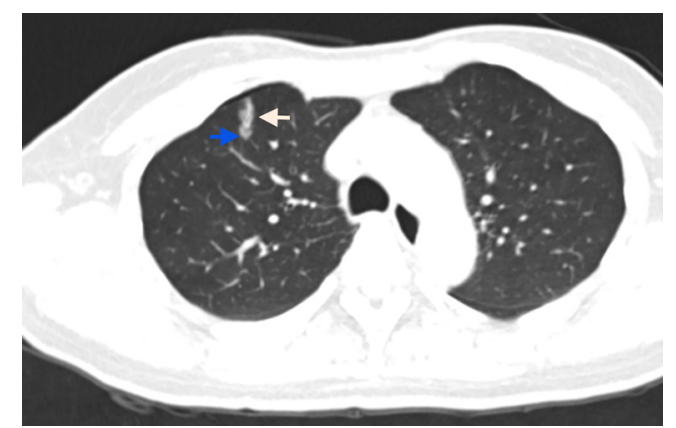

Figure 4 Indocyanine green (ICG; white arrow) is injected around the ground-glass nodule (GGN; blue arrow).

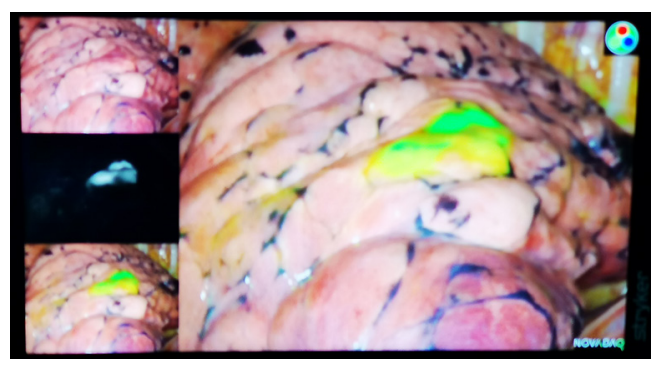

Figure 5 Indocyanine green (ICG) appears as a green area on the lung surface under infrared fluorescence thoracoscopy.

\section{Surgical procedure}

After the localization procedure was completed, the patients were sent to the operating room for surgery within 24 hours. During the operation, we used an infrared fluorescent thoracoscope (Stryker, Kalamazoo, MI, USA) to observe the lung surface and determine the location and resection range. The ICG marking on the lung was green on infrared fluorescent thoracoscopy (Figure 5). The specimen was dissected immediately after removal, and the nodule location was marked with a silk thread. Frozen pathological examination was performed, and the final excision range was determined from pathologic analysis.

\section{Results}

\section{Localization results}

A total of 471 patients (196 males and 275 females) were included in the study (Table 1). The localization was successfully performed in all patients under CT, with an average localization time of 18 minutes (Table 2). Most of the nodules $(81.1 \%, 415 / 512)$ were localized by 3 limited CT scans with an average radiation dose of $281.5 \mathrm{mGy}$. The localization-related complications included pulmonary hemorrhage $(6.8 \%, 32 / 471)$, pneumothorax $(5.9 \%, 28 / 471)$, hemoptysis $(0.4 \%, 2 / 471)$, and pleural reaction $(0.4 \%$, $2 / 471$ ). None of the patients needed tube thoracotomy, with the pneumothorax being $<30 \%$ and not expanding in any of the cases. Patients with complications received oxygen therapy and serial chest X-ray. All complications were resolved without invasive procedure.

\section{Operation results}

All patients underwent thoracoscopic surgery without further thoracotomy, 504 (98.4\%) nodules were rapidly and accurately resected, and in 8 nodules $(1.6 \%)$, the observation was affected due to the diffusion of ICG in the thorax. However, 1 case, we successfully resected the nodule through accurate localization using the pinhole on the surface of the lung; 2 cases underwent segmentectomy; and in 5 cases, the nodule was found after lobectomy. Conversion to thoracotomy for accurate palpation of the lung was judged useless in these patients. All surgical margins were negative. The operation mode and final pathological results are shown in Table 3.

\section{Discussion}

CT-guided localization is the most widely used method for marking small lung nodules for resection. This approach requires percutaneous placement of metal markers, with the most commonly used method being hook-wire or micro coil $(15,16)$. However, metal markers can migrate and may be dislodged in the body. If they move into the chest, they are easy to find; however, if they move into the chest wall, 
Table 1 Basic characteristics of patients

\begin{tabular}{|c|c|}
\hline Characteristic & Value \\
\hline Total number (patients/nodules) & $471 / 512$ \\
\hline Age, mean [range] (years) & $50.8[21-84]$ \\
\hline \multicolumn{2}{|l|}{ Gender, n (\%) } \\
\hline Male & $196(41.6)$ \\
\hline Female & $275(58.4)$ \\
\hline \multicolumn{2}{|l|}{ Smoking history, n (\%) } \\
\hline Yes & $58(12.3)$ \\
\hline None & $413(87.7)$ \\
\hline Nodule size, mean [range] (mm) & $9.1[6-20]$ \\
\hline Distance from nodule to pleura, mean [range] $(\mathrm{mm})$ & $8.9[1-30]$ \\
\hline \multicolumn{2}{|l|}{ Nodule location, n (\%) } \\
\hline Right upper lung & $187(36.5)$ \\
\hline Right middle lung & $10(2.0)$ \\
\hline Right lower lung & $93(18.2)$ \\
\hline Left upper lung & $137(26.8)$ \\
\hline Left lower lung & $85(16.6)$ \\
\hline \multicolumn{2}{|l|}{ Nodule nature, n (\%) } \\
\hline Pure ground-glass opacity & $361(70.5)$ \\
\hline Mixed ground-glass opacity & $121(23.6)$ \\
\hline Solid nodule & $30(5.9)$ \\
\hline
\end{tabular}

$\mathrm{mm}$, millimeter.

their removal is exceedingly challenging due to risks of pneumothorax, pulmonary hemorrhage, pleural reaction, or fatal air embolism (17-19). An alternative to metal markers is CT-guided injection of liquid agents, including methylene blue, contrast agent, lipiodol, radionuclide, etc. $(20,21)$. However, injection of these agents may be inaccurate when the dye diffuses to rapidly, some agents may affect pathological assessment, and, in rare cases, the agents can lead to serious complications such as iatrogenic vascular embolism (22).

The ICG infrared fluorescence localization method has become popular in recent years. ICG is safe, has very low toxicity and rate of allergy $(0.01 \%)(23)$, and has been approved by the Food and Drug Administration. As a watersoluble molecule, it binds to plasma protein after entering the blood stream. It is then rapidly absorbed by the liver cells, enters the biliary tract with bile in free form, and is
Table 2 CT localization characteristics of patients

\begin{tabular}{|c|c|}
\hline Characteristic & Value \\
\hline \multicolumn{2}{|l|}{ CT localization time, mean [range] (min) } \\
\hline All & $18.0[10-47]$ \\
\hline 1 nodule $(n=434)$ & $16.9[10-32]$ \\
\hline 2 nodules $(n=33)$ & $31.1[25-40]$ \\
\hline 3 nodules $(n=4)$ & $43.5[40-47]$ \\
\hline \multicolumn{2}{|l|}{ CT scan times of single nodule, $\mathrm{n}(\%)$} \\
\hline 3 & $415(81.1)$ \\
\hline 4 & $68(13.3)$ \\
\hline 5 & $26(5.1)$ \\
\hline 6 & $3(0.6)$ \\
\hline Mean single nodule radiation $\left(\mathrm{mGy}^{\star} \mathrm{cm}\right)$ & $281.5 \pm 130.3[81-336]$ \\
\hline \multicolumn{2}{|l|}{ Localization-related complications, n (\%) } \\
\hline Pulmonary hemorrhage & $32(6.8)$ \\
\hline Pneumothorax & $28(5.9)$ \\
\hline Hemoptysis & $2(0.4)$ \\
\hline Hemothorax & 0 \\
\hline Pleural reaction & $2(0.4)$ \\
\hline Closed thoracic drainage required & 0 \\
\hline Localization failed & $8(1.7)$ \\
\hline
\end{tabular}

finally discharged through the intestine. Okusanya et al. (24) first used this technique in the localization of pulmonary nodules during operation. The method consisting of CTguided percutaneous ICG injection and intraoperative near-infrared spectroscopy localization of small nodules is safe and feasible (25). This method offers surgeons ease of localization through direct ICG fluorescence imaging, and the ICG does not need to be removed from the lung as with other markers that must be removed together with pulmonary nodules during operation (e.g., hook wire, coil, radioactive tracer, iodine and barium, positioning glue).

ICG localization has other advantages. First, the percutaneous procedure is simple and fast. The average localization time of a single nodule is 16.9 minutes, and the basic procedure of localization is similar to that of percutaneous transthoracic biopsy (26). Second, the success rate of localization before VATS is very high $(98.4 \%$ in this study), and the resection success rate is $100 \%$. Under the 
Table 3 Surgical characteristics of patients

\begin{tabular}{lc}
\hline Characteristic & $\mathrm{N}(\%)$ \\
\hline Anesthesia mode & $224(47.6)$ \\
Nonintubated intravenous anesthesia & $247(52.4)$ \\
Intubated anaesthesia & \\
Number of incisions & $185(39.3)$ \\
Single portal & $286(60.7)$ \\
Two portal & \\
Operation mode & $359(70.1)$ \\
Wedge resection & $80(15.6)$ \\
Segmentectomy & $23(4.5)$ \\
Wedge + segmentectomy & $44(8.6)$ \\
Wedge + lobectomy & $6(1.2)$ \\
Segmentectomy + lobectomy & \\
Pathology & \\
Benign & $48(9.4)$ \\
Atypical adenomatous hyperplasia & $289(56.4)$ \\
Adenocarcinoma in situ & $99.1)$ \\
Minimally invasive adenocarcinoma & \\
Invasive adenocarcinoma & \\
Small cell lung cancer & \\
\hline & \\
\hline
\end{tabular}

near-infrared fluorescence thoracoscope, ICG can be easily recognized on the lung surface, and VATS is convenient and fast. Third, this technique is very safe. In our study, there were no allergic reactions. Fourth, this method does not require drug injection into the pulmonary vessels, which may cause pulmonary embolism, or injection into pulmonary nodules, which may affect the pathological diagnosis. Fifth, after localization, there is no concern that ICG will be absorbed too quickly. In our study, 5 patients did not undergo surgery within 24 hours after localization for various reasons: 3 patients could not be operated on within 24 hours due to an excessive number of operations on that day, 1 patient did not undergo surgery due to contralateral pneumothorax, and 1 patient refused surgery but then did eventually agree. Thus far, we have observed that ICG can remain on the lung surface for up to 6 days (27), which allows for flexibility in the arrangement of the operation time.
Our experience in localization can be summarized as follows: (I) we used a 19-gauge needle injection, which does little damage to the lung tissue. Localization complications included asymptomatic pneumothorax in 28 cases $(5.9 \%)$ and substantial bleeding in 32 cases $(6.8 \%)$, none of which required additional intervention. The incidence of these complications was much lower than that caused by other materials. (II) For peripheral complex nodules, we used the axial localization method, which, combined with anatomical mark localization, can improve localization accuracy. (III) For multiple nodules, we used 2 puncture localizing needles to localize 2 nodules at the same time, avoiding repeated needle pulling, because, in the case of pneumothorax, it is difficult to localize the remaining nodules. (IV) We decided upon a needle depth of 1-2 $\mathrm{cm}$ below the pleura, because in 5 cases of localization failure, the tip of the needle was placed at an insufficient depth below the pleura, resulting in extensive leaking of ICG into the pleural cavity. If ICG is injected too deeply under the pleura, it may not be observable on the lung surface; conversely, if the injection is not sufficiently deep, ICG tends to leak and spread to the chest. In addition, ICG should be injected slowly, and $2 \mathrm{~mL}$ of air should be injected last to prevent ICG from seeping out of the needle channel.

One limitation of this study is its retrospective design, which might have introduced selection bias. In addition, CT-guided localization is an invasive procedure, which can induce anxiety in patients before operation, increasing the radiation dose they receive. The average radiation dose of our study was $281.5 \mathrm{mGy}$. In addition, there was some distance between the CT room and operating room, which could have increased the transport risk. Finally, although the localization procedure is relatively simple, the puncture path needs to be carefully designed to avoid repeated CT scanning and repeated puncture in order to prevent increased radiation and a higher incidence of complications, respectively (28).

\section{Conclusions}

This study represents the largest series of preoperative CT-guided percutaneous ICG injection lung nodule localizations for minimally invasive surgical resection. Percutaneous localization of peripheral SPNs by ICG is easy and quick to perform, and can achieve a high success rate with minimal complications. This technique should be considered prior to minimally invasive pulmonary resection 
for small nodules.

\section{Acknowledgments}

The authors appreciate the academic support from the AME Lung Cancer Collaborative Group.

Funding: None.

\section{Footnote}

Reporting Checklist: The authors have completed the STROBE reporting checklist. Available at http://dx.doi. org/10.21037/tlcr-21-425

Data Sharing Statement: Available at http://dx.doi. org/10.21037/tlcr-21-425

Conflicts of Interest: All authors have completed the ICMJE uniform disclosure form (available at http://dx.doi. org/10.21037/tlcr-21-425). The authors have no conflicts of interest to declare.

Ethical Statement: The authors are accountable for all aspects of the work in ensuring that questions related to the accuracy or integrity of any part of the work are appropriately investigated and resolved. The ethics committee of the First Affiliated Hospital of Guangzhou Medical University waived institutional review board approval. All procedures performed in this study involving human participants were in accordance with the Declaration of Helsinki (as revised in 2013), and informed consent was provided by all patients.

Open Access Statement: This is an Open Access article distributed in accordance with the Creative Commons Attribution-NonCommercial-NoDerivs 4.0 International License (CC BY-NC-ND 4.0), which permits the noncommercial replication and distribution of the article with the strict proviso that no changes or edits are made and the original work is properly cited (including links to both the formal publication through the relevant DOI and the license). See: https://creativecommons.org/licenses/by-nc-nd/4.0/.

\section{References}

1. Swensen SJ, Jett JR, Hartman TE, et al. Lung cancer screening with CT: Mayo Clinic experience. Radiology 2003;226:756-61.
2. Aberle DR, Adams AM, Berg CD, et al. Reduced lungcancer mortality with low-dose computed tomographic screening. N Engl J Med 2011;365:395-409.

3. Heuvelmans MA, Walter JE, Peters RB, et al. Relationship between nodule count and lung cancer probability in baseline CT lung cancer screening: The NELSON study. Lung Cancer 2017;113:45-50.

4. Pedersen JH, Ashraf H, Dirksen A, et al. The Danish Randomized Lung Cancer CT Screening Trial-Overall Design and Results of the Prevalence Round. J Thorac Oncol 2009;4:608-14.

5. Naidich DP, Bankier AA, MacMahon H, et al. Recommendations for the management of subsolid pulmonary nodules detected at CT: a statement from the Fleischner Society. Radiology 2013;266:304-17.

6. Shimizu K, Ikeda N, Tsuboi M, et al. Percutaneous CTguided fine needle aspiration for lung cancer smaller than $2 \mathrm{~cm}$ and revealed by ground-glass opacity at CT. Lung Cancer 2006;51:173-9.

7. Hur J, Lee HJ, Nam JE, et al. Diagnostic accuracy of CT fluoroscopy-guided needle aspiration biopsy of groundglass opacity pulmonary lesions. AJR Am J Roentgenol 2009;192:629-34.

8. Liu L, Zhang LJ, Chen B, et al. Novel CT-guided coil localization of peripheral pulmonary nodules prior to video-assisted thoracoscopic surgery: a pilot study. Acta Radiol 2014;55:699-706.

9. Wicky S, Dusmet M, Doenz F, et al. Computed tomography-guided localization of small lung nodules before video-assisted resection: Experience with an efficient hook-wire system. J Thorac Cardiovasc Surg 2002;124:401-3.

10. Powell TI, Jangra D, Clifton JC, et al. Peripheral lung nodules: fluoroscopically guided video-assisted thoracoscopic resection after computed tomographyguided localization using platinum microcoils. Ann Surg 2004;240:481-8; discussion 488-9

11. Lenglinger FX, Schwarz CD, Artmann W. Localization of pulmonary nodules before thoracoscopic surgery: value of percutaneous staining with methylene blue. AJR Am J Roentgenol 1994;163:297-300.

12. Moon SW, Wang YP, Jo KH, et al. Fluoroscopy-aided thoracoscopic resection of pulmonary nodule localized with contrast media. Ann Thorac Surg 1999;68:1815-20.

13. Chella A, Lucchi M, Ambrogi MC, et al. A pilot study of the role of TC-99 radionuclide in localization of pulmonary nodular lesions for thoracoscopic resection. Eur J Cardiothorac Surg 2000;18:17-21. 
14. Cen RL, Cui F, Wan Q, et al. Preoperative localisation of pulmonary ground-glass opacity using medical adhesive before thoracoscopic resection. Eur Radiol 2018;28:4048-52.

15. Ichinose J, Kohno T, Fujimori S, et al. Efficacy and Complications of Computed Tomography-Guided Hook Wire Localization. Ann Thorac Surg 2013;96:1203-8.

16. Hu L, Gao J, Chen C, et al. Comparison between the application of microcoil and hookwire for localizing pulmonary nodules. Eur Radiol 2019;29:4036-43.

17. Park CH, Han K, Hur J, et al. Comparative Effectiveness and Safety of Preoperative Lung Localization for Pulmonary Nodules: A Systematic Review and Metaanalysis. Chest 2017;151:316-28.

18. Hwang S, Kim TG, Song YG. Comparison of hook wire versus coil localization for video-assisted thoracoscopic surgery. Thorac Cancer 2018;9:384-9.

19. Horan TA, Pinheiro PM, Araujo LM, et al. Massive gas embolism during pulmonary nodule hook wire localization. Ann Thorac Surg 2002;73:1647-9.

20. Wang YZ, Boudreaux JP, Dowling A, et al. Percutaneous localisation of pulmonary nodules prior to video-assisted thoracoscopic surgery using methylene blue and TC-99. Eur J Cardiothorac Surg 2010;37:237-8.

21. Hasegawa T, Kuroda H, Sato Y, et al. The Utility of Indigo Carmine and Lipiodol Mixture for Preoperative Pulmonary Nodule Localization before Video-Assisted Thoracic Surgery. J Vasc Interv Radiol 2019;30:446-52.

Cite this article as: $\mathrm{Li} \mathrm{X}, \mathrm{Xu} \mathrm{K}$, Cen R, Deng J, Hao Z, Liu J, Takizawa H, Ng CSH, Marulli G, Kim MP, Cui F, He J. Preoperative computer tomography-guided indocyanine green injection is associated with successful localization of small pulmonary nodules. Transl Lung Cancer Res 2021;10(5):22292236. doi: $10.21037 /$ tlcr-21-425
22. Jin KN, Lee KW, Kim TJ, et al. Computed Tomography Guided Percutaneous Injection of a Mixture of Lipiodol and Methylene Blue in Rabbit Lungs: Evaluation of Localization Ability for Video-Assisted Thoracoscopic Surgery. J Korean Med Sci 2014;29:129.

23. Mao Y, Chi C, Yang F, et al. The identification of subcentimetre nodules by near-infrared fluorescence thoracoscopic systems in pulmonary resection surgeries. Eur J Cardiothorac Surg 2017;52:1190-6.

24. Okusanya OT, Holt D, Heitjan D, et al. Intraoperative Near-Infrared Imaging Can Identify Pulmonary Nodules. Ann Thorac Surg 2014;98:1223-30.

25. Anayama T, Hirohashi K, Miyazaki R, et al. Near-infrared dye marking for thoracoscopic resection of small-sized pulmonary nodules: comparison of percutaneous and bronchoscopic injection techniques. J Cardiothorac Surg 2018;13:5.

26. Chang YY, Chen CK, Yeh YC, et al. Diagnostic feasibility and safety of CT-guided core biopsy for lung nodules less than or equal to $8 \mathrm{~mm}$ : A single-institution experience. Eur Radiol 2018;28:796-806.

27. Li X, Zeng Y, Liu J, et al. Indocyanine Green Remains in the Lung for up to 6 Days. Ann Thorac Surg 2020;110:e385-6.

28. Ohno Y, Hatabu H, Takenaka D, et al. CT-guided transthoracic needle aspiration biopsy of small $(<$ or $=20$ $\mathrm{mm}$ ) solitary pulmonary nodule. AJR Am J Roentgenol 2003;180:1665. 